\title{
Influence of Different Varieties of Water Reducing Agent on the Early Cracking of Concrete
}

\author{
Jingyun $\operatorname{Han}^{1, a}$, Xuyan Song ${ }^{1, b}$ and Ruyuan $\mathrm{Xu}^{2, \mathrm{c}}$ \\ ${ }^{1}$ College of Civil Engineering, Suzhou University of Science and Technology, Suzhou 215011 \\ ${ }^{2}$ Research Institute of Suzhou Concrete Cement Product, Suzhou 215004 \\ ahjy303rz@yahoo.com.cn, bsongxuyan2002@163.com, cxry828@126.com
}

Keywords: water reducing agent; concrete; cracking; flat-panel test method; limiting shrinkage

\begin{abstract}
Early cracking performance of concrete incorporating five different varieties of water reduce agent was tested by flat-panel test method and concrete surface cracks were observed within 24hours after pouring of concrete. The results showed that crack resistance of concrete incorporating polycarboxylate-based water reducer (PC) was the best, the anti-cracking grade of concrete was Grade I. Followed by those concrete incorporating resin water reducing agent, melamine $(\mathrm{SM})$, naphthalene-based water reducer and aliphatic water reducer, the anti-cracking grade of concrete were all Grade III. Sodium lignosulfonate had greater impact on the early cracking resistance of concrete, initial cracking time earlier and the number of cracks per unit area of concrete greater within $24 \mathrm{~h}$. The anti-cracking grade of concrete with it was Grade IV.
\end{abstract}

\section{Introduction}

Application of admixtures in concrete practice shows that water reducer can affect volume stability of concrete which will directly lead to concrete cracks. Fractures are the major cause of the premature destruction of concrete structures, which will shorten the building structure life. Therefore, the problem about water reducer increasing concrete shrinkage has aroused attention of some scholars. Published literature [1,2] indicates that different varieties of admixtures have a significant effect on concrete shrinkage rate. The literature $[3,4]$ studied the influence of water reducer on volume stability of concrete, which showed that water reducer could increase the shrinkage of concrete, especially, the greater increase in shrinkage within 24 hours. In this paper, test carried out in accordance with the China Civil Engineering Society standard CCES 01, Durability Design of Concrete Structures and Construction Guidelines, which appendix A "test methods and evaluation of concrete cracking resistance" recommended flat-panel test method [5]. Five different kinds of water-reducing agent were mixed with concrete. Flat-panel test method can provide information to assess the effect of different varieties of water-reducing agent on early cracking of concrete by direct observation of concrete cracks and provide a reference for the correct choice of water-reducing agent in concrete works.

\section{Raw materials}

Cement, with strength grade of P.O 42.5, was produced by Shanghai conch cement. Grade I fly ash was provided by Suzhou Wangting power plant and in its chemical compositions both total content of $\mathrm{SiO}_{2}$ and $\mathrm{Al}_{2} \mathrm{O}_{3}$ can reach $84.48 \%$. Five different kinds of water reducing agent were adopted. wherein resin water reducing agent (SM) and polycarboxylate-based water reducer (PC) were produced by Suzhou Xingbang chemical building materials Co., Ltd. Naphthalene-based water reducer was provided by Shanghai Kao chemical Co., Ltd. Aliphatic water reducer was provided by Shanghai fifty-four Plant and sodium lignosulfonate was produced by Beijing Jiahe wooden Co., Ltd. The property index for five kinds of water reducing agent is listed in Table 1. Fineness modulus of river sand was 2.5 2.6. Particle size of A gravel was $5 \sim 10 \mathrm{~mm}$ and particle size of B gravel was $10 \sim 25 \mathrm{~mm}$. In test, stone A and stone B were mixed in weight ratio of 4 to 6 . 
Table 1 The property index for five kinds of water reducing agent

\begin{tabular}{|c|c|c|c|c|c|}
\hline Variety & Resin/SM & Naphthalene & Polycarboxylate/PC & Aliphatic & Lignosulfonate \\
\hline Property index & & & & & \\
\hline Solid content/\% & 27.5 & 39.7 & 70.8 & 100 & 100 \\
\hline PH value & 7.8 & 8.1 & 7.3 & - & - \\
\hline Adding quantity/\%* & 0.58 & 0.54 & 0.15 & 0.62 & 1.0 \\
\hline
\end{tabular}

*It was adding quantity of each water reducing agent when fresh concrete slump achieved $120 \pm 10 \mathrm{~mm}$.

\section{Test methods}

The test was based on the China Civil Engineering Society standard CCES 01, which appendix A recommended flat-panel test method for testing the crack resistance of concrete.

Specimen. The size of concrete specimen was $600 \mathrm{~mm} \times 600 \mathrm{~mm} \times 63 \mathrm{~mm}$. Four sides of the flat-panel mold was made of 10/6.3 unequal angle iron, each side of the angle iron was fixed two rows of $\varphi 10 \mathrm{~mm} \times 100 \mathrm{~mm}$ bolts extending toward inside of the mold. Two rows of bolts were mutually staggered. When the concrete slab specimen contracted during hydration and hardening process, these bolts would limit the contraction of concrete slab.

Concrete mix proportion. Concrete mix proportion is given in Table 2, water-cement ratio was 0.41. The dosage of each water reducing agent was adjusted to maintain slump value of fresh concrete at $120 \pm 10 \mathrm{~mm}$. The adding quantity of each water reducing agent is shown in Table 1 .

Table 2 Concrete mix proportion $/ \mathrm{kg} / \mathrm{m}^{3}$

\begin{tabular}{|c|c|c|c|c|}
\hline Cement & Fly-ash & Sand & Gravel & Water \\
\hline 285 & 85 & 680 & 1035 & 152 \\
\hline
\end{tabular}

Testing. Preparing concrete according concrete mix proportion in Table 2 and mixing respectively with different varieties of water reduce agent in it to adjust concrete slump at $120 \pm 10 \mathrm{~mm}$. Pouring fresh concrete in flat-panel mold and immediately covering the concrete surface with plastic film after vibrating compaction.

The test environment temperature was of $30 \pm 2^{\circ} \mathrm{C}$ and the relative humidity of $60 \%$. Plastic film on the concrete specimen was removed after pouring concrete for 2 hours. A fan with wind speed of $8 \mathrm{~m} / \mathrm{s}$ was used to blowing concrete surface at the same time. Concrete surface was observed, once every $5 \mathrm{~min}$. When concrete surface cracks were found, concrete surface was observed once every $10 \mathrm{~min}$. Initial cracking time, the number of cracks, crack width and crack length were recorded for a course of 24 hours. Finally, a diagram of crack development on the concrete specimen was drawn.

Evaluation of anti-crack performance. After the end of crack observation for $24 \mathrm{~h}$, the three parameters including average crack area on the concrete specimen (a), the number of cracks per unit area of concrete (b) and total crack area per unit area of concrete (c) were calculated in accordance with the formula listed in Table 2. Cracking performance evaluation criteria: 1. Only very fine cracks. 2. Average crack area (a) less than $10 \mathrm{~mm}^{2}$. 3. The number of cracks per unit area of concrete (b) less than $10 / \mathrm{m}^{2}$. 4. Total crack area per unit area of concrete (c) less than $100 \mathrm{~mm}^{2} / \mathrm{m}^{2}$. Early crack resistance of concrete was divided into five grades in accordance with the above four criteria: Grade I should meet all of the above four conditions, and grade II should meet three of the four conditions, and grade III should meet two of the four conditions, and grade IV should meet one of the four conditions, and grade $\mathrm{V}$ should meet no one.

\section{Results and discussion}

Influence of different varieties of water reducing agent on the early cracking of concrete. The concrete volume shrink due to surface water evaporation after the concrete molding. When the contraction stress generated by capillary negative pressure is greater than the tensile strength of concrete, early (24 hours) plastic shrinkage cracks appear on the surface of concrete. There are 
many factors affecting the early plastic cracks of concrete such as varieties of cement, aggregates, water and cement ratio, admixtures, and the environment etc. in which the impact of different varieties of admixtures on concrete shrinkage is greater. The impact results of five kinds of reducing water agent on the early cracking of concrete are listed in Table 3. Cracking schematic of concrete with three kinds of water reduce agent for $24 \mathrm{~h}$ is seen in Figure 1.

Table 3 The impact results of five kinds of reducing water agent on the early cracking of concrete

\begin{tabular}{|c|c|c|c|c|c|c|}
\hline $\begin{array}{c}\text { Reducing water } \\
\text { agent }\end{array}$ & $\begin{array}{c}\text { Initial } \\
\text { cracking } \\
\text { time } \\
/ \mathrm{min}\end{array}$ & $\begin{array}{c}\text { Maximum } \\
\text { crack width } \\
/ \mathrm{mm}\end{array}$ & $\begin{array}{c}\text { Average crack } \\
\text { area } / \mathrm{mm}^{2} \\
a=\frac{1}{2 N} \sum_{i}^{N} W_{i} \cdot L_{i}\end{array}$ & $\begin{array}{c}\text { Number of } \\
\text { cracks per } \\
\text { unit area } \\
b=\frac{N}{A}\end{array}$ & $\begin{array}{c}\text { Total crack area } \\
\text { per unit } \\
\text { area } / \mathrm{mm}^{2} / \mathrm{m}^{2} \\
C=a \cdot b\end{array}$ & $\begin{array}{c}\text { Grade of } \\
\text { anti-cracking }\end{array}$ \\
\hline Resin/SM & 245 & 0.25 & 3.53 & 22.22 & 78.44 & III \\
\hline Naphthalene & 240 & 0.15 & 4.42 & 13.89 & 61.39 & III \\
\hline $\begin{array}{c}\text { Polycarboxylate } \\
\text { /PC }\end{array}$ & 252 & 0.12 & 1.08 & 5.56 & 6.00 & I \\
\hline Aliphatic & 247 & 0.15 & 4.75 & 11.11 & 52.77 & III \\
\hline Lignosulfonate & 202 & 0.17 & 7.4 & 16.67 & 123.36 & IV \\
\hline
\end{tabular}

Note: In fracture parameter formula, $W_{i}$-Maximum width of crack i, mm; $L_{i}$-The length of the crack i, mm; $N$-The total number of cracks on a concrete flat; $A$-concrete flat area, $0.36 \mathrm{~mm}^{2}$.

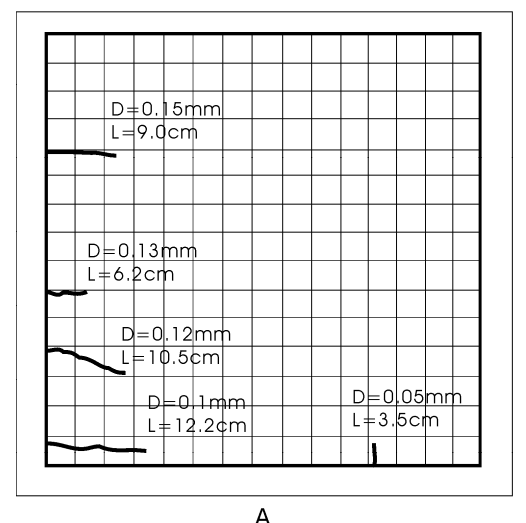

Fig.1 Cracking schematic of concrete with three kinds of water reduce agent for $24 \mathrm{~h}$

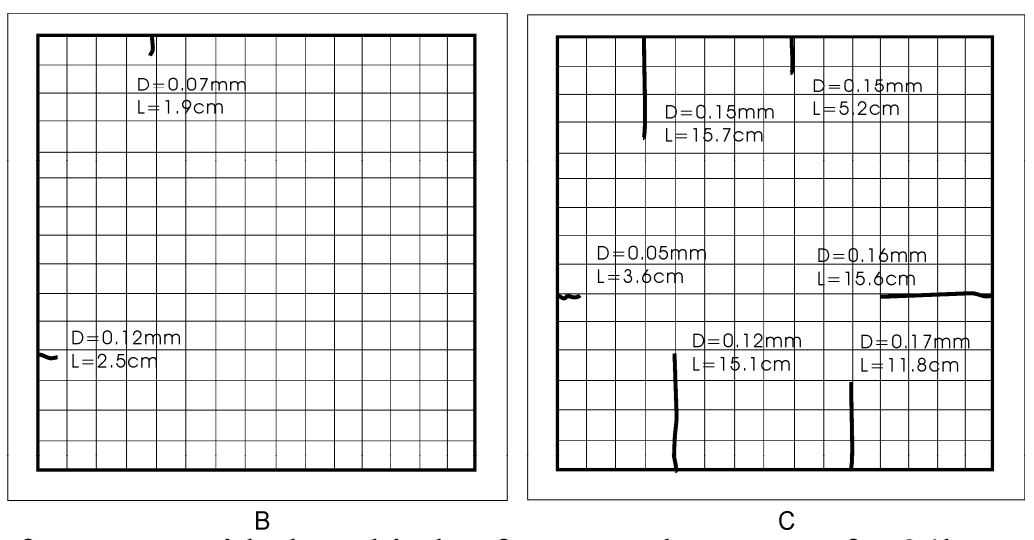

$\mathrm{B}$ - Polycarboxylate (PC) C-Sodium lignosulfonate

Influence of different varieties of water reducing agent on the initial cracking time of concrete. The initial cracking time of concrete incorporating polycarboxylate (PC) water-reducing agent was later than that of concrete incorporating other four kinds of water reducing agent. The initial cracking time of concrete incorporating sodium lignosulfonate was the shortest. The initial cracking time of concrete respectively incorporating aliphatic, melamine (SM) and naphthalene-based water reducer were almost the same. Sodium lignosulphonate tended to cause concrete initial cracking time short because it had a significant retarding action on concrete, and concrete could not be formed early structural strength to resistant shrinkage stress so that concrete in the deformation process by the inhibition of the model steel screw produced plastic cracks.

Influence of different varieties of water reducing agent on the maximum crack width of concrete. It can be seen from Table 3 that the maximum crack width of concrete incorporating four kinds of water reducing agent except melamine water reducing agent (SM) are $0.15 \mathrm{~mm}$ or so. The crack only stretched to the length and the crack width would no longer develop until the end of the test. The crack width of concrete incorporating SM water reducing agent is the largest, the width of 8 cracks on the concrete slab are all $0.25 \mathrm{~mm}$. The length of 8 cracks did not exceed the screw constraint area. The reason was that the first crack of the concrete appeared later, the concrete of the non-restricted zone has reached a certain intensity to resist crack stretching at this time. Therefore, the cracks can only expand in the constraint area. Contrast to the concrete incorporating sodium lignosulphonate, the initial crack appears, although the crack width is not increased, but cracks 
rapidly extending to the non-inhibited area, more than 10 centimeters in length.

Influence of different varieties of water reducing agent on the average crack area and total crack area per unit area of concrete. The two parameters including average crack area and total crack area per unit area of concrete can basically reflect plastic cracking performance of concrete. The two parameters for the concrete incorporating sodium lignosulphonate were the largest among the concrete incorporating other kinds of water reducing agent and the two parameters for the concrete incorporating polycarboxylate (PC) were smaller. This indicated that the polycarboxylate as a kind of water reducing agent had little effect on the plastic cracking of concrete.

Influence of different varieties of water reducing agent on the crack resistance grade of concrete. It can be shown from Table 3 that crack resistance grade of concrete incorporating water reducing agent in descending order was that polycarboxylate-based water reducer (PC), melamine water reducing agent (SM), naphthalene-based water reducer, aliphatic water reducer, sodium lignosulfonate. Test results were consistent with the literature published $[1,2,6]$. Because the water-reducing agent could make water-cement ratio of concrete lower while the fresh concrete maintained the same mobility. Thus the capillary pressure and shrinkage stress inside concrete increased during plastic stage of concrete. Once shrinkage stress exceeded early tensile strength of concrete, concrete plastic shrinkage cracking was produced. If water-reducing agent delayed setting time of concrete, this phenomenon may be more obvious. Typically, the polycondensation type water-reducing agent like naphthalene-based would increase the contraction of concrete, copolymer type water-reducing agent containing reducing contraction groups, such as polycarboxylic etc. would reduce concrete shrinkage. The test results also confirmed this assertion.

\section{Conclusion}

Plastic cracking performance of concrete incorporating five kinds of different varieties water reduce agent was tested by flat panel mold method. The results showed that the influence of different varieties of water reduce agent on the anti-plastic cracking performance of concrete was differences. Among them, the crack resistance of the concrete incorporating polycarboxylate-based water reducer (PC) was the best, the crack resistance grade of concrete was Gradel. Followed by the concrete incorporating resin water reducing agent, melamine (SM), naphthalene-based water reducer and aliphatic water reducer, the crack resistance grade of concrete were all Grade III. Sodium lignosulfonate had greater impact on the early cracking resistance of concrete, initial cracking time earlier and the number of cracks per unit area of concrete greater in $24 \mathrm{~h}$. The anti-cracking grade of concrete with it was Grade IV.

\section{Acknowledgements}

This work was financially supported by Research Project of Suzhou Construction Organization (Z1574).

\section{References}

[1] C.W. Miu. Chemical Industry Press (2008).

[2] S.F. Han and W.S. Geng. Chemical Industry Press (2004).

[3] X.Q. Qian, S.L. Zhan, M.H. Fang, etc.. Concrete admixture and its application technology Conference(2004), p.79-86.

[4] X.Q. Qian, S.L. Zhan, M.H. Fang, etc.. Railway Science and Engineering, (2004), p.21-27.

[5] China Civil Engineering Society standard CCES 01. Chinese Building Industry Press (2005).

[6] Z.H. Fei, D.X. Cui and H.T. Yao. Concrete and cement products, (2011), p.19-21. 